\title{
Predictive Data Mining Model for Electronic Customer Relationship Management Intelligence
}

Bashar Shahir Ahmed, Computer Science and Systems Engineering Laboratory, University Abdelmalek Essaadi, Tetouan, Morocco

(iD) https://orcid.org/0000-0001-9192-8960

Mohamed Larabi Ben Maâti, Computer Science and Systems Engineering Laboratory, University Abdelmalek Essaadi, Tetouan, Morocco

Mohammed Al-Sarem, College of Computer Science and Engineering, Taibah University, Medina, Saudi Arabia

(iD) https://orcid.org/0000-0001-7172-8224

\begin{abstract}
The rising adoption of e-CRM strategies in marketing and customer relationship management has necessitated to more needs especially where a specific customer segment is targeted and the services are personalized. This paper presents a distributed data mining model using access-control architecture in a bid to realize the needs for an online CRM that intends to deliver web content to a specific group of customers. This hybrid model utilizes the integration of the mobile agent and client server technologies that could easily be updated from the already existing web platforms. The model allows the management team to derive insights from the operations of the system since it focuses on e-personalization and web intelligence hence presenting a better approach for decision support among organizations. To achieve this, a software approach made of access-control functions, data mining algorithms, customer-profiling capability, dynamic web page creation, and a rule-based system is utilized.
\end{abstract}

\section{KEYWORDS}

Access, Agent, Data, E-Business, E-CRM, Engine, Mining, Predictive, Web

\section{INTRODUCTION}

The current business world has adopted-to a larger extent, the concept of e-business where companies utilize the internet platform for interactions and effective communication with their customers. This has increased the interaction points compared to the initial face-to-face interactions. E-CRM is a technique employed to create a loyal online customer relationship (Berry \& Linoff, 2004). Using the technique, it is also possible to discover the best and most rewarding way of realizing such a relationship using the web platform. This is an always growing process for retaining, growing and acquiring loyal and profitable customers using the internet. 
E-CRM, to be specific, focuses mainly in the areas of decision support, customer management and personalized service. Personalized service refers to the provision of better customer service by presenting the right and correct information to the right and intended customers (Berry \& Linoff, 2004). Normally, this is achieved on a web platform (Chua, 2011). This enables the users to acquire the information of their interest hence enhancing the experience of the user on the website. Customer management on the other hand operates through the main internet points of communication between the customer and the company (Chua, 2011). This mainly involves proactive direct communication to the customers via emails, newsletters and even interactive online help desk. This may also include automation of sales force (Chua, 2011) (Figure 1).

Figure 1. e-CRM covers three business areas and their functions

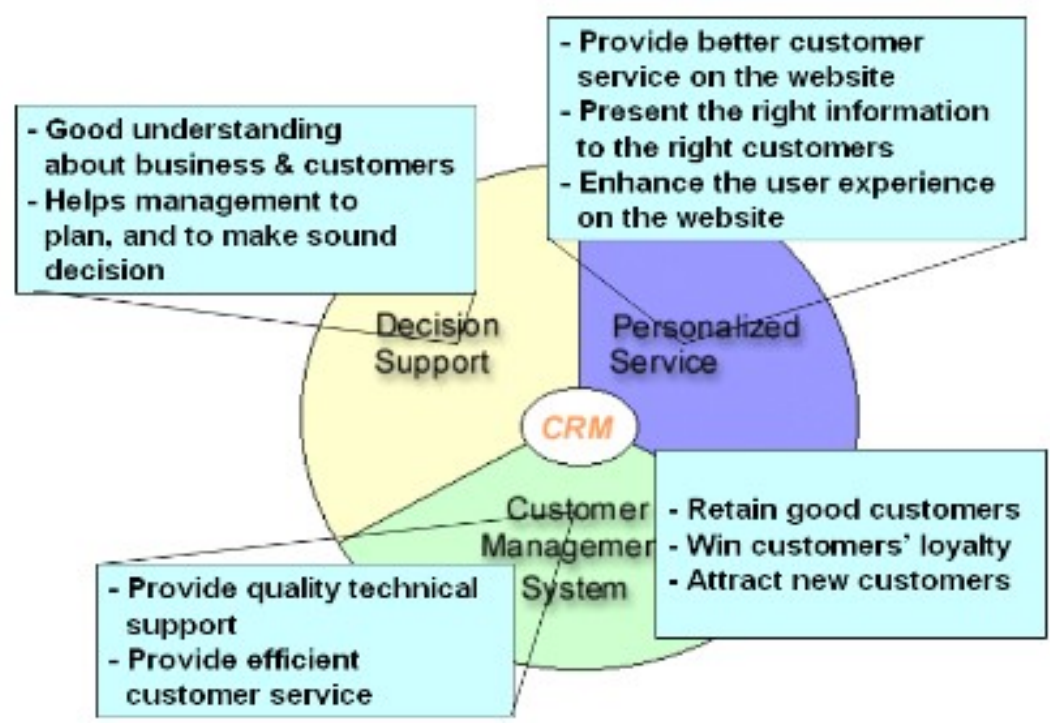

For sound decisions by management on how to better run e-CRM, it is important that one has a better understanding of the business operations and the targeted customer base. Effective business intelligence is that which has been obtained timely. Due to the ever-changing pace of e-business, the information has been evolving too. These business areas together assist in the retaining and attraction of loyal customers (Berry \& Linoff, 2004).

Generally, this paper appreciates the three main technologies of web log analyzer, web spy and data-warehousing (includes decision support modules and data-mining modules). This is in regard to the targeted areas of personalized service and decision support. Each of the technologies gives some better insight into the aspects of the business. Most particularly, use of web log analyzer is not enough to give detailed understanding of business intelligence. Nonetheless, it gives a detailed report on the statistics of the website. It is however important that other information like the market positions, customers and their behaviors and competitor information. In this article, the knowledge on the customer will be utilized in the e-personalization of the web content based on the customer's needs (Berry \& Linoff, 2004).

In order to attain the objectives as depicted in Figure 2, the Access-control architecture is proposed (Bashar Ahmed, M.L. Ben Maâti, \& Badreddine Al Mohajir, 2014). This can be built on an existing 


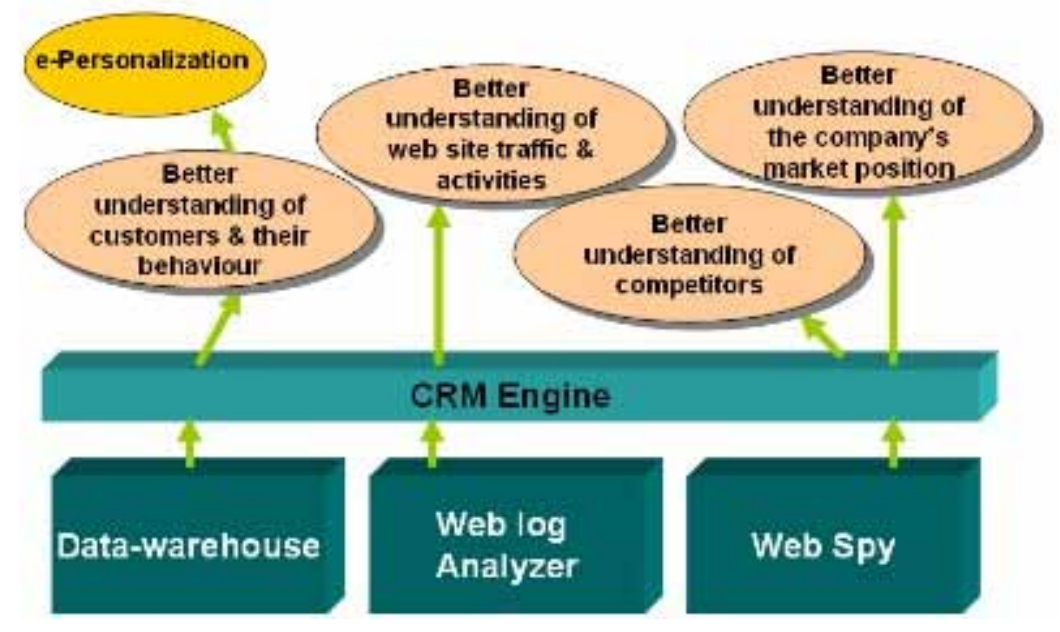

website. The key objective is to distribute the functions of business intelligence and e-CRM with the help of an agent-architecture. Another objective is to monitor the accesses by the users on the website.

\section{RELATED WORK}

Predictive Analytics are all about finding the insights that will help you understand what might happen in the future. They help you recognize patterns in historical data, repeated transactions, and relationship cues. If you use predictive analytics effectively, you can facilitate a more proactive business approach.

There is a gigantic and horrifying sea of predictive analytic research \& theory out there - so much so that it could make your head spin. So, for the sake of sanity, let's hone-in on three of the major predictive analytics types and how they can make you a smarter, savvier, sales or marketing professional (Danine Midura, 2016).

The three predictive analytics we're going to discuss are shown below.

\subsection{Sequencing}

Simply put, sequencing has to do with analyzing probability, sequencing refers to the ability to acquire knowledge of the structure of sequences. This can be achieved incidentally acting on event sequences through experience or, in case of explicit efforts, intentionally. To learn a sequence means that the presentation and ordering rules of stimuli must be acquired. The working memory system comes into play by keeping the information on a single stimulus active, allowing comparison with subsequent stimuli. In addition, the relationships among the temporal and spatial characteristics of the stimuli must be acquired. Of relevance is the need to store the sequence structure once identified.

\subsection{Cross-Selling}

What do you see when you make a purchase on a website like Amazon? As you go to check out, it shows you suggestions such as: People who bought this TV also bought this HD cable and these DVDs. They're using analytic data to figure out which companion products you're most likely to need/ want based on your purchase - it's cross-selling. You can use predictive analytics in the same way.

Just as people who buy a TV often end up needing cables, people who buy one of your products or services may end up needing a companion product. Look back through transactional data from the 
last two years to see which products were most often purchased together. Then, use your predictive analytics strategy to plan the cross-sell strategy.

\subsection{Lack of Action}

The first two predictive analytics we covered have to do with interpreting the data around a customers' actions. But, have you thought about the uses of predictive analytics for the opposite? If a customer you have frequent interactions with suddenly wanes in their communication, there may be a problem. Perhaps they're unsatisfied with something, or worse, they are thinking of severing business ties. Best case scenario, save the relationship, but you can't know to do that without first realizing there's a problem. So look back on the customers who have left you. Can you pull out any patterns or trends? Use those patterns to create a fall-off model. For example, if you notice customers tend to respond slower (or not at all) to your emails prior to dropping your business, you can factor that in to your fall-off model. Think of your fall-off model as the ying to your analytics yang. When you combine the patterns from fall-off with your sequencing data, you can start to predict whether someone is likely or unlikely to buy. If they're more likely to buy, the marketing and sales departments can reach out to encourage the final push.

As the trend towards predictive analytics continue, the activity management and sales forecasting of organizations will evolve to match. As humans, we are creatures of habit. Our behavior patterns tend to remain steady, and if you learn to read those patterns, you can vastly improve the effects of your sales and marketing efforts. Many E- CRM systems are starting to offer predictive analytics capabilities to keep up with this trend. Infor E-CRM, Salesforce, and Microsoft have all introduced predictive analytics in their latest releases, and another major E-CRM player, SugarCRM has one in the works. When it comes to predictive analytics, there's no time like the present! Use the power of your information for smarter sales and marketing, starting now.

\section{THE HYBRID ACCESS CONTROL ARCHITECTURE}

In this section, a presentation of the hybrid model for data mining in business intelligence is done. This is in a bid to realize the easy integration and web server upgrade for operation in e-business environment. The unique features of this framework include; the integration of the distributed software agents and the website's access monitoring system for the users. This promotes the mining ability to be performed on the remote sites with the help of the mobile agents giving business reports that are insightful and intelligent. The result is also fed back to a remote rule based system for e-personalization. This makes it able for adoption on existing websites (Berry \& Linoff, 2004).

This model operates on the principle of allowing the website with little modifications to capture the user's trails, their particulars and allowing them better service experience online through e-Personalization. Because of this, it has the option for using the mobile-agent model and client-server model. The following are the components of the proposed hybrid AC architecture.

\section{1. e- Business Website}

This is mainly composed of the personalization server and the web server. The latter hosts the website and handles users' http requests. It is on this platform that the e-CRM and distributed data mining can be implemented (Berry \& Linoff, 2004). This made is possible by upgrading it to an agent-based architecture. It is the web server that is responsible for storing the submitted online forms, logs and the profile of the users. On the other hand, generation of dynamic web-pages is made possible by the e-Personalization server.

\section{2. e-CRM Server}

This server stores operational data by serving as a repository for data mining agents. 


\subsection{OLAP Agent}

This generates data-cubes that are multi-dimensional for browsing information and which could be integrated on a separate extranet or intranet server in a bid to allow access for authorized personnel only (Berry \& Linoff, 2004).

\subsection{Web Alert Agent}

This mainly allows alert broadcast to the designated company personnel in case of exceptional events (Berry \& Linoff, 2004). For instance, when the value of a given data channel exceeds a given threshold, a given group of people in the company receive short messages or email addresses as a notification of the event.

\subsection{Web Spy Agent}

This has the functionality for spying on the websites of the online competitors by retrieving information like new products, prices, their market positions and even updates.

\subsection{Data-Mining Agent}

It is evident from the agent components' illustrations above; the three major areas of business are covered as depicted in the Figure 3. The main focus of this paper is on how the access control and login mechanism can be implemented on the website to realize enhanced business information and e-CRM integrated with framework of E-CRM Application and Customer Behavior (Bashar Ahmed, M.L. Ben Maâti, \& Badreddine Al Mohajir, 2015).

Figure 3. Agent based framework for business intelligence and e-CRM

\section{Decision Support}

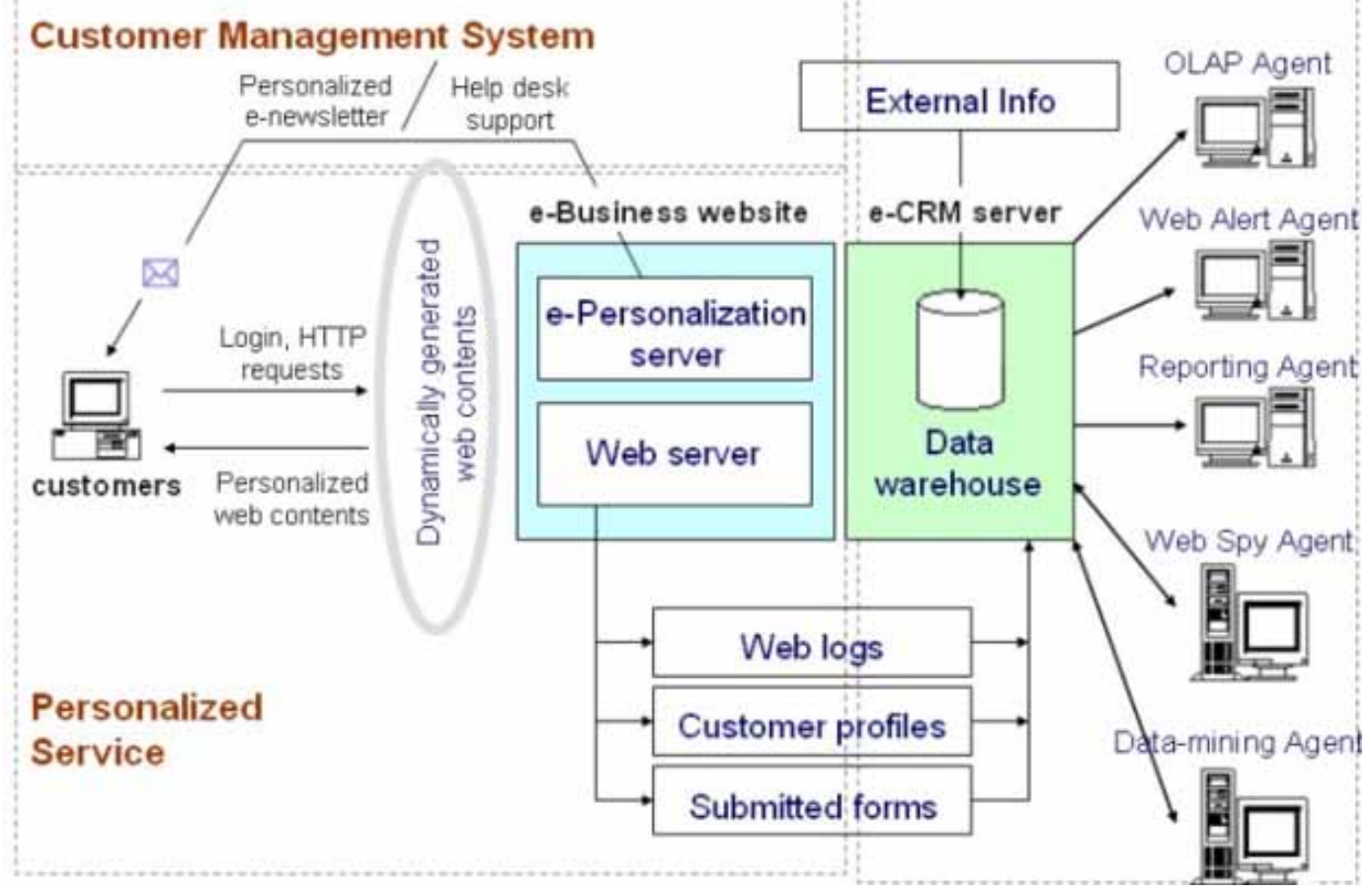




\section{THE ACCESS CONTROL MECHANISM}

This is a requirement in the implementation of website that is e-CRM enabled and one that has customer centered intelligence. Basically, it requires a login for access grant to protected functions. On the initial, the user would be required to register with a password and a user name of his/her choice. The hypertext links to resources that are protected on the web site are then modified with any click on these hyperlinks being recorded in a database (Fjermestad \& Romano, 2006). The recorded information involves the user, time logged in and the resources accessed. This information would be significant in the provision of insights on the activities on the website rather than traffic hits on every visit. The flowcharts in Figure 4 and Figure 5 illustrate the login and access procedures and in each case the information is recorded in two different database tables.

Figure 4. Flow for login procedure

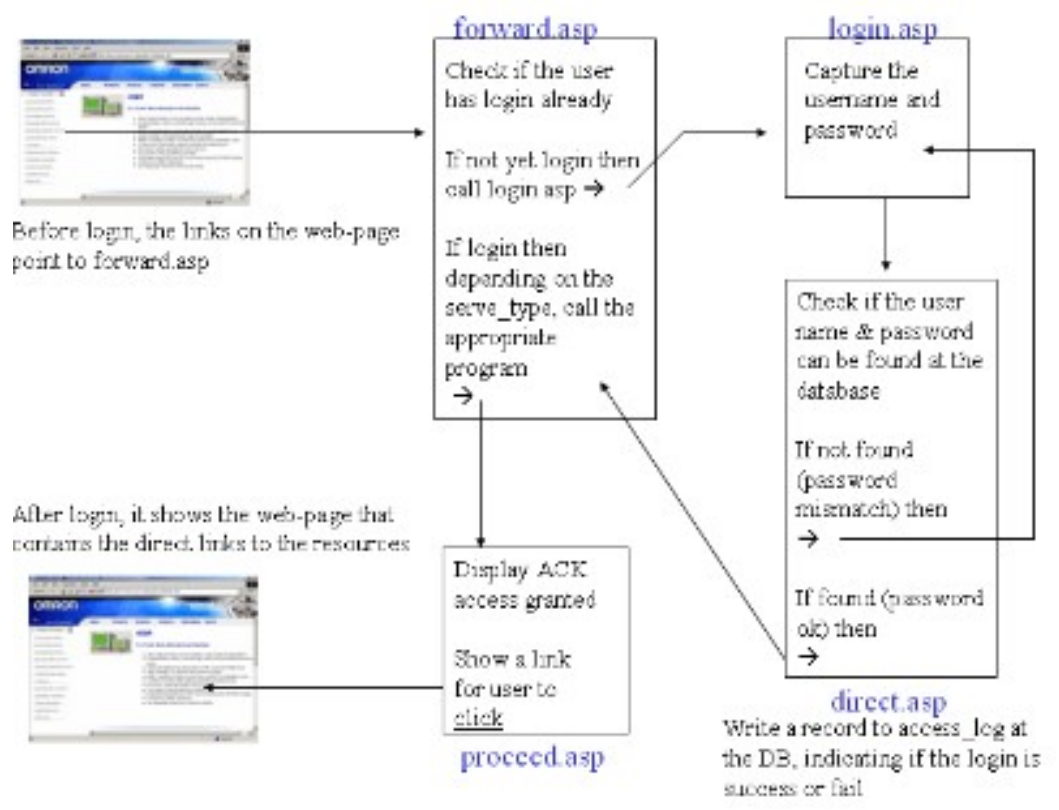

Figure 5. Logical flow for access procedure
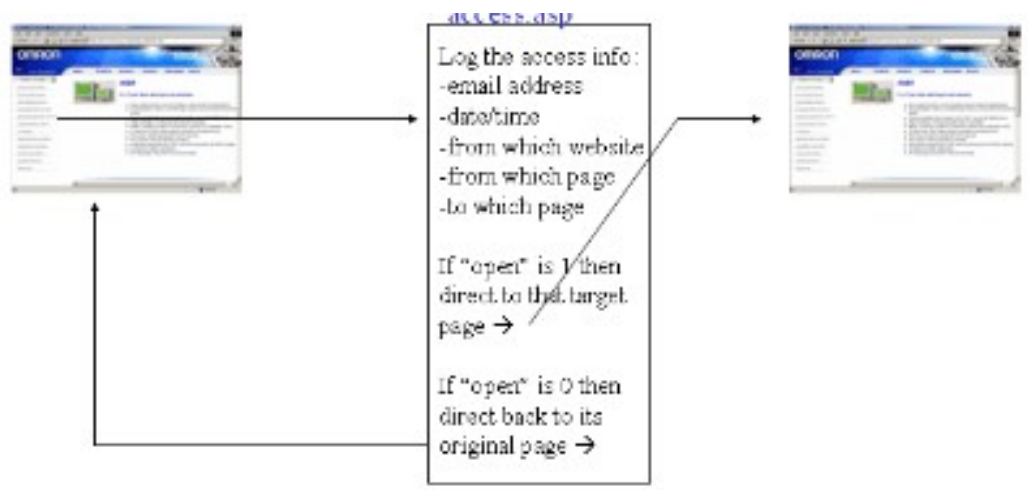
The distinguishing feature for AC architecture is that the specific resources to be monitored on a page can be accurately pinpointed. Access patterns to these resources can then be derived and monitored (Fjermestad \& Romano, 2006). This leads to the ability for a company to obtain a wealth of business intelligence. This is possible with the aid of data mining and even without. In both, information about product popularity, customers' interests and technical knowledge base could be derived.

\section{PATTERN DISCOVERY WITH AC ARCHITECTRURE}

Pattern discovery is also referred to as web usage mining. It's the process for mining for access and user browsing patterns. With this proposed method, mining is painted as backend process that is significant for deriving business intelligence (Iyer \& Bejou, 2004). Before the mining algorithms may be run, the below issues ought to be addressed in the pre-processing of data.

\subsection{The Preprocessing Task}

Here, the server log is cleaned to do away with irrelevant attributes. Issues like proxy servers and local caches could distort the intended picture of user traversals in a website. In order to overcome this problem, cookies and cache browsing are some of the modern implemented techniques used. In the AC environment, user accesses derived from the links are recorded and an assurance is made that the user has logged in and that he/she has shared his unique userid before he is allowed access. Hence, every record stored grasps the detailed information on user's identification, the time of access and the accessed resource. With this technique, the data preprocessing effort is minimal. This method is more reliable as there is no ambiguous value. The main drawback, however is in getting the users to sign up. For that matter, the value of the resource must be worthy the user's login effort.

Discovery techniques on Web Transactions

There exists a number of mining techniques that could be performed on the access records. Good examples include classification, clustering and path analysis (Figure 6).

\section{CONTRIBUTION TO KNOWLEDGE}

There already exists a couple of e-CRM technologies aimed at improving service delivery and interaction experiences between the companies and customers. For these to be achieved, both the companies and the customer personnel must have a fair interaction with the e-CRM system. The main focus of this paper was to realize a better interaction experience between the companies and the e-CRM system. The proposed means for data mining is so significant in achieving this milestone. The ability for the intelligent data acquisition out of the system edges away the previous manual means used traditionally. The automation therefore would to a very larger extent improve the level of interaction experience between the company personnel and the system. For this reason, it would be possible for the organizations to understand their client base and patterns helping in intelligent decision making and service provision. This paper adds relevant knowledge in this area and the proposed framework is much more advocated for.

\section{CONCLUSION}

For businesses that have adopted e-Business, it is a vital business function to enhance the effectiveness of their sites and this can be derived from their ability to accurately the site's traffic and to monitor the visitor's activities. The discussed access control technique rides on this key discovery: the ability to obtain data from the links to the resources at the web server rather than manual search from the 
Figure 6. Code excerpt for a sample login form

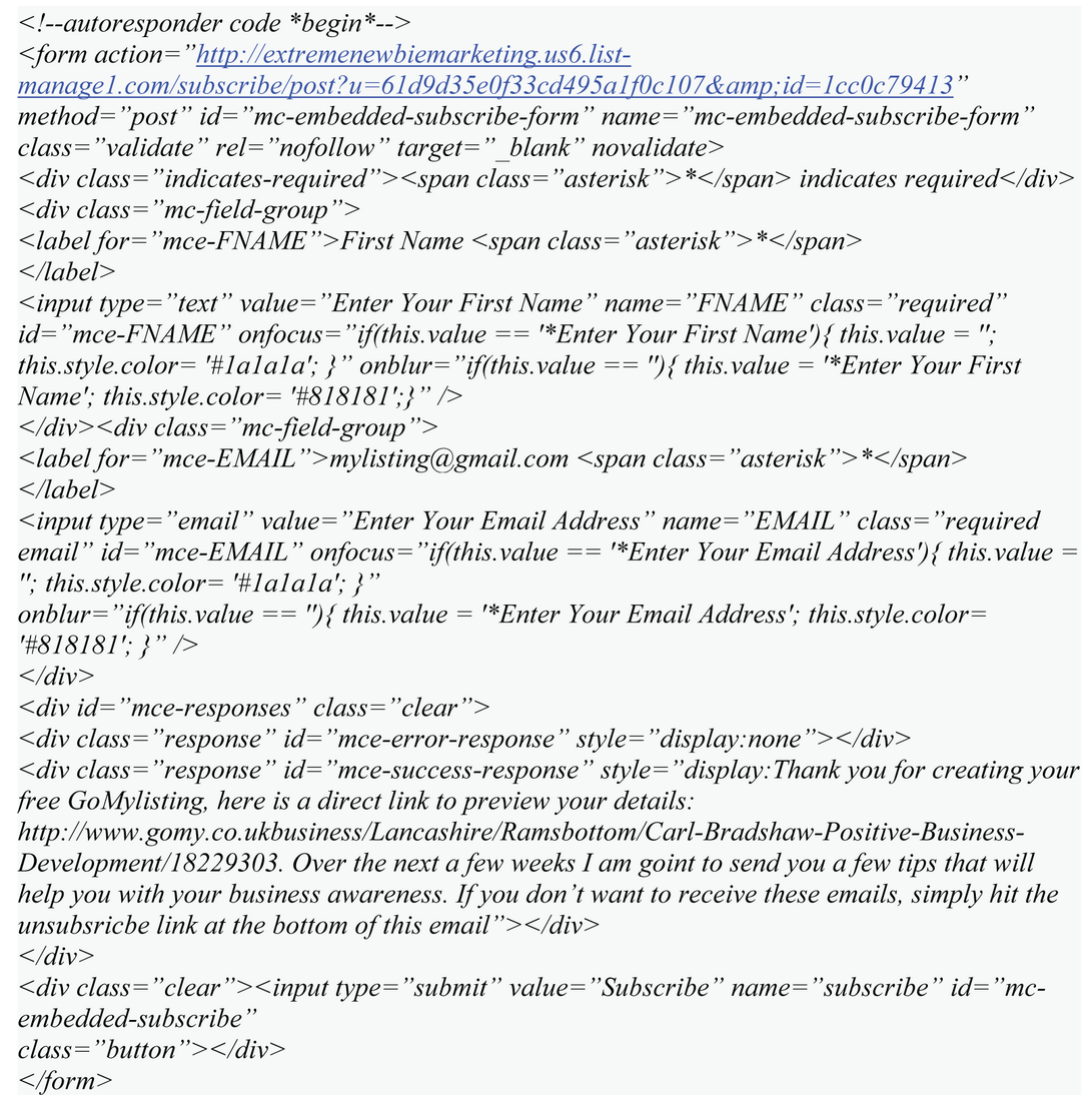

servers' log files. It's a login based approach for getting clients' trails. An assumption is made that the users get to login in exchange for the underlying valuable information and resources. This framework provides a better and a more reliable intelligence to the company owners.

\section{FUTURE DIRECTIONS}

Predictive analytics is one of many emerging technologies with applications in E-CRM and other sectors. This powerful technology, which has also been used in various applications in the medical field, travel safety and the automotive and travel industries, enables consumers as well as businesses and their employees to make more informed decisions. Moreover, it is a reliable tool that helps to improve business relations.

Although predictive analytics is mostly used to analyze consumer behavior, it will be much more diverse and customizable in the near future. The opportunities for predictive analytics, which was once predominantly used by telecoms and finance companies, will certainly continue to grow. As capabilities seek to expand, the ability to predict behavior and analyze risks will be the standard for many companies to have a competitive advantage. 


\section{REFERENCES}

Ahmed, B., Maâti, M. L. B., \& Al Mohajir, B. (2014). The Intelligence of E-CRM Applications and Approaches on Online Shopping Industry. International Journal of Innovation and Scientific Research, 12(1), 213-216.

Ahmed, B., Maâti, M. L. B., \& Al Mohajir, B. (2015). Improve Intelligence of E-CRM Applications and Customer Behavior in Online Shopping. International Journal of Business Intelligence Research, 6(1), 1-10. Advance online publication. doi:10.4018/IJBIR.2015010101

Anderson, K., \& Kerr, C. (2002). Customer relationship management. McGraw-Hill.

Batenburg, R., \& Versendaal, J. (2007). Business/IT-alignment for customer relationship management: Framework and case studies. IJECRM, 1(3), 258. doi:10.1504/IJECRM.2007.017795

Berry, M., \& Linoff, G. (2004). Data mining techniques. Wiley.

Busaidi, K. (2013). Aligning customer knowledge management tools with business strategy. IJECRM, 7(2), 117. doi:10.1504/IJECRM.2013.056510

Chen, T., \& Lin, Y. (2009). Enhancing the relationship benefit to develop relationship value. IJECRM, 3(2), 167. doi:10.1504/IJECRM.2009.025286

Chen, T., \& Ling, Y. (2008). Customer relationship management resources and practices and customer voluntary behaviour: The evidence of passengers at Taiwan's international airport. IJECRM, 2(3), 276. doi:10.1504/ IJECRM.2008.020412

Chua, A. (2011). How Web 2.0 supports customer relationship management in Amazon. IJECRM, 5(3/4), 288. doi:10.1504/IJECRM.2011.044693

Cunningham, M. (2002). Customer relationship management. Capstone Pub.

Fjermestad, J., \& Romano, N. (2006). Electronic customer relationship management. M.E. Sharpe.

Gosney, J., \& Boehm, T. (2000). Customer relationship management essentials. Prima Tech.

Guimaraes, T., \& Paranjape, K. (2014). Testing cloud computing for customer satisfaction and loyalty. IJECRM, 8(1/2/3), 72. doi:10.1504/ijecrm.2014.066885

Iyer, G., \& Bejou, D. (2004). Customer relationship management in electronic markets. Best Business Books.

Iyer, G., \& Bejou, D. (2004). Customer Relationship Management in Electronic Markets. Journal of Relationship Marketing, 2(3-4), 1-13. doi:10.1300/J366v02n03_01

Jham, V. (2009). An empirical investigation of customer satisfaction with multi channel banking. IJECRM, 3(2), 121. doi:10.1504/IJECRM.2009.025283

Jones, S., \& Ranchhod, A. (2007). Marketing strategies through customer attention: Beyond technology-enabled Customer Relationship Management. IJECRM, 1(3), 279. doi:10.1504/IJECRM.2007.017797

Low, K., \& Anshari, M. (2013). Incorporating social customer relationship management in negotiation. IJECRM, 7(3/4), 239. doi:10.1504/IJECRM.2013.060700

Madhani, P. (2011). Marketing and supply chain management integration: Strategic implications for enhancing customer value proposition. IJECRM, 5(2), 153. doi:10.1504/IJECRM.2011.041263

Manchanda, P., Dube, J., Goh, K., \& Chintagunta, P. (n.d.). Banner Advertising as a Customer Retention Tool in Customer Relationship Management. SSRN Journal. doi:10.2139/ssrn.468120

Midura. (2016). Predictive Analytics for CRM. www.techadv.com/blog/3-predictive-analytics-crm

Muther, A. (2002). Customer relationship management. Springer. doi:10.1007/978-3-642-56222-8

Nguyen, B., \& Mutum, D. (2012). Customer relationship management: Advances, dark sides, exploitation and unfairness. IJECRM, 6(1), 1. doi:10.1504/IJECRM.2012.046467

Nykamp, M. (2001). The customer differential. AMACOM. 
Peel, J. (2002). CRM. Digital Press.

Powell, M., \& Childerhouse, P. (2010). Retail value stream management. IJECRM, 4(3), 209. doi:10.1504/ IJECRM.2010.035963

Raab, G. (2008). Customer relationship management. Gower.

Ranjan, J., \& Agarwal, R. (2009). Application of segmentation in customer relationship management: A data mining perspective. IJECRM, 3(4), 402. doi:10.1504/IJECRM.2009.029298

Sastry, M. (2007). Integrated Outage Management System: An effective solution for power utilities to address customer grievances. IJECRM, I(1), 30. doi:10.1504/IJECRM.2007.014424

Shah, M. (2008). Fuzzy logic: A realistic tool for management of customer relation. IJECRM, 2(2), 158. doi:10.1504/IJECRM.2008.019930

Sinisalo, J., \& Karjaluoto, H. (2007). Mobile Customer Relationship Management: A communication perspective. IJECRM, 1(3), 242. doi:10.1504/IJECRM.2007.017794

Warriorforum.com. (2015). How do I add my autoresponder code to a prebuilt form on a squeeze page template? Retrieved 24 June 2015, from https://www.warriorforum.com/website-design/716479-how-do-i-add-myautoresponder-code-prebuilt-form-squeeze-page-template.html

Bashar Shahir A. Ahmed, PhD, works in The Intelligence of e-CRM Dept. Informatique Faculty of Science, Tétouan University of Abdelmalek Essadi, Morocco.

Mohamad Larabi Ben Maâti is a teacher of Computer Science at the Faculty of Science in Tetouan. He completed his studies at the University Louis Pasteur of Strasbourg (in France) where he obtained his PhD in Computer Science in 1994. Right now Dr. Maâti is the coordinator of the Master Software Quality at the Faculty of Sciences of Tetouan. His research topics are: Images encryption, image processing, machine learning, eCRM (electronic customer relationship management), ERP (Enterprise Resource Planning) in Web2.

Mohammed Al-Sarem received the M.S. degree in Information Technology from the Faculty of Informatics and Computer Engineering, Volgograd State Technical University, Volgograd, Russia, and the Ph.D. degree from the Faculty of Informatics, University of Hassan II Casablanca-Mohamadia, Mohamadia, Morocco, in 2007 and 2014, respectively. He is currently an Associate Professor with the Information System Department, Taibah University, Al Madinah Al Munawarah, Kingdom of Saudi Arabic. He published several papers and participated in managing several international conferences. His current research interests include group decision making, multi-criteria decision making, data mining, E-learning, natural language processing and social analysis. 